\title{
Innovative Teaching Using Simulation and Virtual Environments
}

\author{
Joseph Barjis \\ Delft University of Technology, \\ Delft, The Netherlands \\ j.barjis@tudelft.nl \\ Ramesh Sharda \\ Oklahoma State University, \\ OK, USA
}

ramesh.sharda@okstate.edu

\author{
Peggy D. Lee \\ Indiana University-Kelley \\ School of Business, \\ Indianapolis, IN, USA \\ pedalee@iupui.edu
}

\author{
Ashish Gupta \\ Minnesota State University \\ Moorhead, MN, USA \\ gupta@mnstate.edu
}

Tatiana Bouzdine-Chameeva

BEM- Bordeaux Management School, France

tatiana.chameeva@bem.edu

\author{
Alexander Verbraeck \\ Delft University of Technology, \\ Delft, The Netherlands
}

a.verbraeck@tudelft.nl

\begin{abstract}
Simulation and game-based techniques are becoming increasingly popular methods of inquiry into complex service-science-related problems and phenomena. Integrating these techniques and models into the curriculum allows for students to visually learn about the objects of their study and the related concepts, interact with processes, components, and systems, and understand the underlying dynamic behavior of the objects of their study. Such a learning experience is usually difficult to build using more traditional approaches such as case studies and experiential exercises. In this paper, after a brief introduction, we discuss the authors' experience in using simulation and game-based and virtual environments, such as Second Life and Innov8, that lead to a more innovative teaching of service science concepts. The proposed approaches can have positive im-

Material published as part of this publication, either on-line or in print, is copyrighted by the Informing Science Institute. Permission to make digital or paper copy of part or all of these works for personal or classroom use is granted without fee provided that the copies are not made or distributed for profit or commercial advantage AND that copies 1) bear this notice in full and 2) give the full citation on the first page. It is permissible to abstract these works so long as credit is given. To copy in all other cases or to republish or to post on a server or to redistribute to lists requires specific permission and payment of a fee. Contact Publisher@InformingScience.org to request redistribution permission.

plications for the quality of education in areas such as Business, Management Information Systems (MIS) and Systems Engineering and may be a significant step towards a more comprehensive students' learning experience. We include some preliminary students' learning outcomes that indicate potential of one game-based learning technique that we describe in the study. We also briefly illustrate how a more formal approach
\end{abstract}


such as causal mapping can be used to develop a robust and effective curriculum using the example of Operations Management.

Keywords: modeling, simulation, game-based learning, Second Life, education, curriculum design, causal mapping, operations management

\section{Introduction}

Modern service systems are complex, multi-actor systems of a distributed nature. For teaching and studying how interactions, decisions, and collaboration of different parties are managed when designing and deploying complex systems, simulations and game-based learning approaches are gaining popularity (Corsi et al., 2006; Saunders, Rutkowski, van Genuchten, Vogel, \& Molina Orrega, 2011). Several research studies have reported on the shortcomings of traditional lectureoriented and case-study-based pedagogical or training approaches (Bransford, Brown, \& Cocking, 2000; Coldwell, Craig, \& Goold, 2011; Hake, 1998; Maerki, 2008). The absence of technical components from education and training is being considered a major contributing factor to the lack of preparedness or skills that are deemed extremely important for a vast majority of professionals who need to make complex decisions in highly-paced, dynamic work environments. The National Science Foundation (NSF) and other government agencies have recently reported on the abysmally low ranking of U.S. undergraduates in terms of technical skills (Mayo, 2009; National Science Board, 2012). Such deficiencies may be partially overcome by integrating a combination of simulation modeling and game-based learning approaches, utilizing the availability of ubiquitous computing tools and technologies, into modern-day teaching and training curricula. As Mayo (2009) and Zyda (2007) suggest, such integration tends to lead to an effective learning paradigm, enriched brain chemistry, and significant improvement in the learning outcomes and cognition.

The educational use of immersive games and simulation models of situations and problems similar to those found in the real world leads to trainer-less and unsupervised learning (Zyda, 2007). Further, it prepares an individual for making decisions in extreme and complex social and networked environments or situations such as defense applications and disaster management. In other words, modeling and simulation can serve as useful tools for teaching decision making skills both in single- and multi-actor environments. Also, several evolving disciplines such as service sciences are presently in their infancy stages but emerging at a tremendous pace. Such interdisciplinary areas that have their roots in disciplines such as operations management, computer science, and information systems can benefit tremendously from simulations and game-based approaches. At present, simulation modeling and game-based approaches are widely adopted only for studying and teaching concepts and applications that are otherwise difficult to explain. However, their adoption into mainstream college education and training still lags.

This paper reports on the findings related to the above stated issues that have been documented by a group of collaborating co-authors teaching at different universities. The group was focused on innovative approaches that have been inspired by simulations (Seppanen \& Kumar, 2002), gamebased approaches (Royle, 2008; Yang, Smith, \& Graham, 2008), and virtual environments such as Second Life, Innov8, Active Worlds, and Proterra (Foster, 2008; Marcus \& Ray, 2006). These tools and approaches can be especially successful in and convenient for teaching Operations Management, Management Information Systems, and service sciences, as well as systems engineering in general. Essentially, this paper explores and demonstrates the application of interactive tools, namely, simulation modeling, game-based approaches, and virtual environments, in teaching. Another goal is to highlight the need for and value of these tools in complex, networked, multi-actor decision-making processes.

Being a collaborative endeavor, this paper intends to launch a discussion on the use of virtual environments or tools to support the learning process. In doing so, each co-author contributed 
his/her experience with a particular environment and/or tool. Some of the experiences were documented and reported based on the collected data, whereas the others were more based on the authors' reflection and expert opinion on the use of a particular tool in a classroom.

This article is organized as follows: in the next section, we provide a brief review of simulation modeling, game-based approaches, and virtual environments as potential tools for reinforcing learning experience and implementing interactive and reflective learning. In the core part of the paper, we discuss simulation modeling (Innov8), virtual environments (Second Life), and Causal Mapping. Each of these subsections draws on the reflections and pedagogical research, experiences, and thoughts of the authors. After that, the paper not only discusses the tools and virtual environments but also includes an innovative application of Causal Mapping to ensure that course design and the design efficiency are scientifically measured through the achievement of learning outcomes. Next, based on the previous sections, and especially on the discussion of the first hand experiences, we indicate some implications and opportunities for using simulation modeling,

game-based approaches, and virtual environments in teaching. Finally, we summarize the purpose and contribution of this paper and elaborate on the need and direction for future research.

\section{Literature Review: Evolution of Simulation and Game-Based Approaches in Teaching}

The new generation of students, surrounded from an early age by computers, animations, computer games and graphics, and dominated by virtual interactions, can conveniently and effectively learn when they interact, visually observe, and actively participate in learning processes (Byrne, Catrambone, \& Stasko, 1999). Therefore, innovative teaching would be hard to imagine without the support and use of technology tools such as audio-visual and virtual interactive tools and environments - simulation, visualization, animation, and immersive game-based approaches. Below, we discuss application of game-based learning and simulation as applied in management and business fields.

In the field of decision support systems (DSS), the assistance offered to users in their complex, non-routine, and semi- or unstructured decision-making tasks is driven solely by quantitative models such as simulations and analytical formulations (Power \& Sharda, 2007). This particular category of DSS is specifically referred to in the literature as 'model-driven DSS'. Simulations and game-based approaches are classic examples of model-driven DSS. Decisions that are based on simulation models often follow the classical Gorry and Scott Morton's DSS (Gorry \& ScottMorton, 1989), a decision-making process summarized in Shim et al. (2002). In particular, the creation of any simulation-based DSS involves the first step of problem recognition, which is followed by generation of alternative solutions, simulation model formulation and development, analysis of 'what-if' scenarios, identification of the best option, and finally implementation of the solution. Several types of simulation methodologies can be utilized to make such DSS (see e.g., Tatnall \& Burgess, 2007). For example, Monte-Carlo simulation is a popular simulation technique to help to understand the potential risks and uncertainties in the output variable, given that input parameters come from approximated probability distributions. Discrete event simulations are extensively used to model real world situations where a prior event has to happen to trigger any following event. For example, the line at a cashier moves forward (second event) after the previous customer has been processed (first event). Systems dynamics, also referred to as continuous simulation, uses time as a continuous function and relies heavily on differential equations. Agent-based modeling is a modeling approach where each agent has its own properties and behavior. This technique is mainly used to model multi-actor systems or networks where each actor interacts with the other actors to produce the emergent behavior that is of key interest to scientists. There are several other types of simulation modeling techniques that can be utilized to create simulation based DSS. Usually the nature of the problem under investigation helps determine the 
suitability of a particular technique. For example, simulation is a popular technique for generating data on the system behavior or in the absence of clear distribution patterns of arrivals (Zeigler, Praehofer, \& Kim, 2000), whereas analytical modeling is better suited when the input data can be precisely defined by a distribution function (Aris, 1994; Gershenfeld, 1998)

Game-based approaches in business education have been used in their primitive form for many years and are certainly not new. However, by integrating 3D environments powered by video, audio, and advanced visualization techniques, the next generation of gaming, simulation and model-driven DSS tools can be created. Figure 1 presents our reflection on the development of business games, from traditional to online and global business games. Paper-based games were used in decision making between 1960 and 1980. These games, while lacking realism, were focused on round-based decision making through a comparison of simple business processes and typically involved a small number of players. Computer-supported games were popular from 1980 to 1994. These were round-based as well but could handle increased business-process complexity and more players could simultaneously play the game. The Internet boom started the next generation of games between 1994 and 2005. These games were also round-based but could mimic the real world complexity to a greater extent and were played at a more global level. The post 2005 era is characterized by internet-mediated, simulation-based live games. These 24/7 games can be played globally and use simulation techniques to simulate some parts of the game world. These games have the highest degree of realism and, therefore, support continuous decision making. In the following section, we elaborate on some of the innovative teaching tools and techniques that fall in this genre and have been utilized by the authors.

\begin{tabular}{|c|c|c|c|}
\hline $\begin{array}{l}\text { Paper-based games, } \\
\text { decisions are made in } \\
\text { rounds }\end{array}$ & $\begin{array}{l}\text { Computer-supported } \\
\text { games, round-based }\end{array}$ & $\begin{array}{c}\text { Internet-mediated } \\
\text { games, round-based }\end{array}$ & $\begin{array}{c}\text { Internet-mediated, } \\
\text { simulation-based, live } \\
\text { games }\end{array}$ \\
\hline \multirow{6}{*}{$\begin{array}{l}\text { 1960-1980 } \\
\text { - simple business } \\
\text { process } \\
\text { - small number of } \\
\text { players } \\
\text { - lack of realism } \\
\text { - round-based deci- } \\
\text { sion making }\end{array}$} & \multirow{6}{*}{$\begin{array}{l}1980-1994 \\
\text { - increase in com- } \\
\text { plexity of business } \\
\text { processes } \\
\text { - increase in the } \\
\text { number of players } \\
\text { - computer used as a } \\
\text { calculator }\end{array}$} & \multirow{6}{*}{$\begin{array}{l}1994-2005 \\
\text { - gaming around the } \\
\text { globe } \\
\text { - mimic today's global } \\
\text { complexity } \\
\text { - still round-based }\end{array}$} & $2005-$ \\
\hline & & & $\begin{array}{l}-24 / 7 \text { gaming around the } \\
\text { globe }\end{array}$ \\
\hline & & & - usage of simulation to \\
\hline & & & $\begin{array}{l}\text { simulate parts of the sys- } \\
\text { tem }\end{array}$ \\
\hline & & & $\begin{array}{l}\text { - live gaming, i.e., continu- } \\
\text { ous-based decision mak- } \\
\text { ing }\end{array}$ \\
\hline & & & $\begin{array}{l}\text { - increased engagement } \\
\text { due to a high degree of } \\
\text { realism }\end{array}$ \\
\hline
\end{tabular}

Figure 1: From traditional to live and global business games.

\section{Innovative Teaching - Tools and Approaches}

In this section, we discuss the authors' experiences in using different tools for innovative teaching. As the reader will find, the experience of teaching with the use of simulation, visualization, and game-based approaches demonstrates that sophisticated concepts and abstract notions can be easily explained in an interactive way, and the teaching process can be designed in a more participative and reflective manner. Teaching in a technology-rich environment requires a regimen of pedagogical innovative approaches supported and complemented by tools (e.g., simulation and game-based approaches) (Seppanen \& Kumar, 2002). Nonetheless, we do not claim that tools are the "Silver Bullet" of innovative teaching or the only prerequisite for successful learning. In con- 
trast, tools alone will only hinder the learning process if the deployed teaching approach is not aligned with purpose and outcome of a particular course. Therefore, in the concluding subsection of this section we discuss an innovative approach using Causal Mapping as a mean of measuring the efficiency of a course design based on the students' learning outcome and the course deliverables.

\section{About and Within a Virtual Environment}

Virtual worlds such as Second Life (www.secondlife.com), Active Worlds (www.activeworlds.com), Innov8 (www.ibm.com/software/solutions/soa/innov8.html), and InWorldz (www.inworldz.com) are the next frontier of collaboration, social networking, electronic commerce, and education. Developed as multiplayer, online role-playing games (MMORPG Massively Multiplayer Online Role Playing Games), these 3D virtual worlds have grown exponentially, creating many opportunities and challenges for educators, businesses, social scientists, policy makers, and the legal profession (Foster, 2008; Marcus \& Ray, 2006). Educational institutions from Harvard and MIT to corporate universities have a presence in some virtual world, many of them in the Linden Labs-developed Second Life ("Second Life education directory," n.d.). Educational institutions use virtual environments such as Second Life to extend their resident course offerings into distance education, for student course registration activities, and for online library resources. Since 2007, the work of educators in virtual worlds has been showcased through the Virtual Worlds Best Practices in Education annual conference held in Second Life (http://conf.vwbpe.org). Businesses use Second Life for collaborative activities such as virtual team meetings, employee training, customer support, prototyping and sales activities ("Second Life work/success stories," n.d.). The convergence of almost every media into one platform has been a driving force of this phenomenon. In 2007, the Gartner Group estimated (The Gartner Group, 2007) that by the end of 2011, $80 \%$ of Internet users would be engaged in some form of virtual world technology. Unfortunately, Gartner has not continued this line of research so an update to these data is not available (Pettey, 2012). However, the UK marketing and research firm, KZero, reports that as of the second quarter of 2011, the number of registered users in virtual worlds was over 1 billion (KZero Worldswide, n.d.). Given these statistics, it behooves educators to prepare students for this "brave new world" and teachers themselves to spearhead this innovative learning experience.

\section{What is Second Life?}

Second Life, launched in 2003 by Linden Labs (http://www.lindenlabs.com) of San Francisco, California, is an online, virtual 3D multi-user environment that functions as a virtual world. It is an immersive, social-interaction environment. It is not a game, in that the outputs of the actions of its residents are not predetermined by a set of rules. As of the fourth quarter of 2009 (the last time these data were available), there were 16.9 million residents (i.e., avatars) in Second Life, who have been building communities, creating content, and owning and operating businesses. Linden Labs indicated that there were approximately 750,000 unique users as of third quarter 2010 (Linden Lab, 2011). Social interaction is one of the primary reasons people create avatars (i.e., a real person's virtual persona) in virtual worlds. Research suggests that avatars are extensions of people's real counterparts and that people tend to treat their avatars as if they were in real social space (Bélisle \& Bodur, 2010; De Nood \& Attema, 2006; Suh, Kim, \& Suh, 2011).

Content creation is the fabric of Second Life. Everything that exists is there because a resident or a group of residents created it. Because residents own everything they create, they can market and sell those creations to other residents, creating a thriving economy and a rich environment within which instructors can teach business concepts and skills experientially. Second Life allows professors to provide students with an immersive learning environment hitherto not available in dis- 
tance education. Educators can develop learning activities that replicate real-world experiences that were previously only available via face-to-face interaction. Students can experience simulations of real-life activities from operating a business to building a replica of a university's campus. Students can, using the Second Life scripting and building tools, create their own virtual businesses and communities.

The remainder of this section describes the use of Second Life to enhance the delivery of the core MBA Operations Management course at a major university on the east coast of the United States. This work was a part of a faculty virtual worlds initiative aimed at determining whether virtual worlds could be used in higher education. An assignment that included the use of Second Life was introduced to the class in the very early stages of the use of virtual worlds in general. The Second Life Project is an individual assignment in which students are expected to research a chosen Second Life business type (e.g., retail, real estate, or event planning) and report on their findings. The goals of the project are 1) to experience a virtual business environment; 2) to learn about virtual businesses and compare their operations to the operations of real world businesses of the same type; and 3) to gain an exposure to a Web 2.0 technology. Assignment deliverable takes the form of a paper that compares a virtual business with a real world business and links the virtual operation to one or more Operations Management decision areas. Students are also required to prepare a short presentation of their findings. The presentations are given inside Second Life. Students' work is augmented with (real-world) office hours, guest speakers, and technical assistance provided by the instructor and the university's technical staff. At the end of each 7week term, a survey was administered to each student to determine whether the assignment helped them to attain the learning objectives for the course (see Table 1), to get feedback on the students' experiences in Second Life, and to get the students' opinions about whether this experiential exercise is suitable for an MBA curriculum.

\section{Course structure and the project activities}

As mentioned earlier, this is the core and only Operations Management course in the MBA curriculum at the author's institution. Well over $90 \%$ of the student body is composed of working professionals, the average age being between 28 and 34. Evening classes, lasting 3 hours, are held twice per week, for seven weeks. In this way, students can take two courses in any 14-week period without taking them simultaneously. Due to this highly condensed delivery format, the instructors make heavy use of experiential exercises such as simulations, games, and case studies. The Second Life Project is one of such exercises. The specific activities students must complete within this assignment are:

1. Learn about Second Life from the materials available at its web site and from discussions with the instructor.

2. Create an avatar and a basic (i.e., free) account with Linden Labs.

3. Complete the Second Life Orientation by going to Help Island, which is a place within the $3 \mathrm{D}$ world for residents to get help from Second Life Mentors who are trained for that purpose.

4. Send the instructor an Instant Message from within Second Life with the avatar's name and the student's real name.

5. Attend office hours at least once within the 3D virtual world.

6. Find and join the class group within Second Life.

7. Explore enough of the virtual world to be able to select a business type to study.

8. Find and interview one or more virtual business owners about how their businesses operate. 
9. Compare and contrast the Second Life business type with its real-life equivalent, focusing on operations management issues (e.g., inventory, capacity management, facility location, and queuing).

10. Write a two-page paper with findings.

11. Give an individual presentation at the school's (virtual) space in Second Life.

From the pedagogical perspective, every activity in the assignment is designed to enhance student learning. For example, rather than giving students the names of people to interview about their virtual business operations, students are instructed to explore the Second Life community and meet people on their own. In this way, students learn how to maneuver the 3D virtual world. Students also learn to use the voice chat capability for presenting the results of their interviews. As a consequence of this fairly unscripted approach, students have the freedom and the flexibility to decide how involved they will be in the Second Life community. The minimum level of involvement in the Second Life community is to learn enough about it to be able to select a business type to study and to find and interview a Second Life business owner about the business he/she operates.

The learning curve for becoming "fluent" in Second Life can be steep. We would flatten the learning curve by conducting a class in a computer lab on the second night of the course. The instructor would guide students through the process of creating an avatar and a basic (i.e., free) Second Life account. We would also go through the Second Life orientation and answer any questions the students might have. As each student sent the instructor an instant message with his or her Second Life and real names, the instructor would send a set of "getting started" information. Students could use this information to further explore Second Life. This information also gave them a "head start" on their projects. If enough time remained after each student sent the instant message and received the "getting started" information, students would be allowed to remain in the lab to explore Second Life, with the instructor available to answer questions and provide any assistance. Other pedagogical techniques included optional in-world office hours on the night when face-to-face class was not held. In addition, guest speakers would be scheduled during this time period. Guest speakers were Second Life entrepreneurs. Students were allowed to use the guest speakers' presentations as a basis for their reports and were encouraged by the guest speakers to contact them for a more in-depth interview. Finally, Second Life would be also used for group presentations and debriefings of the Littlefield Technologies, a factory simulation the author also uses to teach Operations Management.

\section{Student research findings and attainment of learning objectives}

The students would present their findings to the class during a session held in Second Life.

Presentations were limited to two minutes so that all students could present their work and answer questions in a three-hour class period. The instructor would use text chat (rather than voice) in order to be able to capture the students' presentations into a word document to be later reviewed for grading. This would also reduce the anxiety level of students with a new technology in that they did not have to learn how to use a headset with Second Life. Students would be given detailed instructions on what to include in their presentations as well as how to prepare their presentations beforehand. Students were not required to use power point slides.

The types of businesses researched by the students were limited only by their imaginations since so many types of businesses are present in Second Life. However, the most prevalent types of firms researched by the 75 students who have participated in this assignment are:

1. Land development and real estate

2. Retail clothing, furniture, etc. 
3. Tours (i.e., guided tours of points of interest in Second Life such as the Second Life Louvre)

4. Amusement parks

5. Sports facilities (triathlon training facility, golf club, health spa)

6. Business center

7. Restaurants, including a pizza delivery place

8. Music venues and dance clubs

On the last day of class, students would complete a survey with questions about their Second Life experience. They would rate (using a 7-point Likert scale) whether they strongly agree (7) or strongly disagree (1) that the Second Life project helped them to attain each of the learning objectives of the course (see Table 1). In general, the students found the project worthwhile, although many were not sure whether it should be a part of an Operations Management class. Most of them stated that virtual worlds are part of the future, so students need to be exposed to them. Some indicated that the project was time consuming and they were at a loss as to how to proceed once they finished the orientation. This feedback was received verbally early in the semester, which is why the instructor began using class time for setting up basic accounts and selecting avatars. As to the attainment of course learning objectives, Table 1 shows results for the 75 students who took the course between September 2007 and April 2008.

Table 1: Attainment of course learning objectives with the use of Second Life

\begin{tabular}{|l|l|}
\hline Learning Objective & $\begin{array}{l}\text { Mean } \\
\text { (scale of 1-7) }\end{array}$ \\
\hline Define Operations Management and its relationship to other disciplines & 4.12 \\
\hline $\begin{array}{l}\text { Ascertain the appropriate product and process design strategies in manu- } \\
\text { facturing and service companies }\end{array}$ & 4.02 \\
\hline $\begin{array}{l}\text { Define and use Total Quality Management (TQM) and Statistical Process } \\
\text { Control (SPC) principles, tools and techniques }\end{array}$ & 3.48 \\
\hline $\begin{array}{l}\text { Make operations management decisions based on quantitative and finan- } \\
\text { cial analyses, including facility location and queuing theory }\end{array}$ & 4.00 \\
\hline $\begin{array}{l}\text { Determine the appropriate inventory control policy to use in specific cir- } \\
\text { cumstances }\end{array}$ & 4.08 \\
\hline Analyze and improve a business process & 4.65 \\
\hline
\end{tabular}

These results were as expected since the focus of the assignment was how virtual businesses operate and the linkage between real and virtual business enterprises. It makes sense that TQM and SPC knowledge scored low and that business process analysis scored the highest. Since a survey was not administered prior to introducing this assignment into the course, a comparison of the course without this assignment can only be determined anecdotally. The instructor found that after this assignment was introduced and the learning curve issues related to Second Life were addressed, the students' overall understanding of Operations Management concepts improved over the previous semesters. She found this to be the reason to continue with the use of this assignment given the intense nature of the course.

Although the presented results indicate that virtual worlds can be used to teach Operations Management, there are some caveats when using a virtual world technology for any purpose. First, 
one has to make sure to have a purpose for the technology. The instructor should decide what learning outcomes are expected and design the project so that students clearly understand those objectives and how the project achieves them. The instructions should be written explicitly. Class time should also be used for the initial introduction to the virtual world so that the instructor can answer any questions and thus reduce the time students need to become fluent. Instructors are advised to spend time exploring and learning about the virtual world on their own prior to using it for instruction because students will see the instructor as the expert. Finally, the use of virtual worlds technology is not for every student, nor every instructor, nor every course. Care should be taken to ensure that there is a good fit with the learning objectives and the course content. In short, the learning objectives drive the technology.

\section{Game and Simulation Based Approaches to Systems Analysis}

In this section we briefly discuss simulation and game-based learning approaches from the perspective of engineering complex systems (infrastructures), where game-based approaches (or serious games) are emerging as tools for study and a mode of knowledge inquiry and theory building.

Simulation and serious games are used as tools for constructivist discovery learning, pioneered by Piaget and Vygotsky (Piaget, 1970; Vygotsky, 1935/1978), where users build their knowledge and educators assist in the knowledge acquisition and building. Mayer and Veeneman (2002) described three uses for serious games: education, intervention and research. For instance, today's advanced Global Supply Chain Game by Van Houten, Verbraeck, Boyson, and Corsi (2005) is suited for business management education (Corsi et al., 2006) and is used today for Operations Management education in many countries (USA, Europe, and Asia). The majority of learning games require minimal facilitation, guidance, or engagement of instructors, thus providing more flexibility and self-learning mode. Although minimally guided learning in general is criticized, e.g., by Kirschner, Sweller, and Clark (2006), for its lack of student support, researchers (e.g., Bekebrede, Mayer, Van Houten, Chin, \& Verbraeck, 2005) find that simulation games are most successful when embedded into a broader research, learning, or intervention process in which a number of complementary methods and activities are used.

Designing and understanding complex engineering systems is a daunting task without first building a virtual prototype. Therefore, courses that teach complex systems design draw extensively on game and simulation based approaches. In the intersection of complex relationships, network interactions, and possible conflicts of interest, managers, policymakers, and politicians involved in infrastructure projects are confronted with many unexpected outcomes of their institutional designs (Mayer \& Veeneman, 2002). Students of systems engineering programs who desire preparation for managerial and leadership positions in infrastructure projects ought to learn professional skills and engineering knowledge that allow them to quickly get the "big picture". In a systems engineering program at the institution of one of the authors, simulation and game-based labs and demos are usually included in addition to the lectures and other conceptual materials that they reinforce.

One simulation model we extensively used in the class is OLS, the Dutch abbreviation for underground logistics system (Heijden et al., 2002). This simulation, which is a mix of simulation and reality, is about a highly automated underground transportation system using automatic guided vehicles (AGVs) around Schiphol Airport. This transportation complex requires many years to implement, an estimated investment of $\$ 250$ to $\$ 500$ million, and is supposed to take place some time in the future. The OLS project is unique in its scale, incorporating 16 to $25 \mathrm{~km}$ tubes connecting five to twenty terminals, with 200 to $400 \mathrm{AGVs}$ to transport, with different ordering priorities, an estimated 3.5 million tons of cargo in 2020. The motivation for the OLS project was the increasing congestion around Amsterdam, which forced the government, in cooperation with 
business partners, including Schiphol Airport, the world's largest flower auction at Aalsmeer, and logistics service providers, to consider underground construction that will connect three modes of transportation: air, rail, and highway.

One of the main things that students can learn from this simulation model is how to manipulate different variables, parameters, and design options for optimal or acceptable solutions. For example, this model showed that an investment reduction of plus or minus 20 percent is feasible using periodically switched one-way tube sections. Also, through this simulation model the researchers developed a variety of logistics-optimization algorithms and heuristics, including allocating AGVs between terminals, scheduling terminals, and controlling traffic. An interesting experiment conducted with the OLS model was a simulation of control structures to test prototype AGVs on a test location. Performing distributed simulations with a mixture of simulated and real objects, students have been shown how to reduce the risks of a new technology, improve performance, get different parties interested, and attract investments.

\section{Designing Simulation Models for Understanding Different Scenarios}

Simulation modeling techniques are becoming increasingly popular as a method of inquiry into several complex scientific problems and phenomena. Some researchers regard these techniques as a third way of doing science by combining induction and deduction methods (Axelrod, 2003). Integrating such techniques and models with a DSS component into the classroom teaching and having students interact with 3D visualizations of these models may be a significant step towards a more complete student learning experience. Students can leverage the potential of these models to make better decisions in real-world situations or explore problems and understand their inherent dynamics by self-exploring different 'if-then-else' scenarios, manipulating various parameters, and later analyzing the output.

The previous section illustrated how an existing simulation model could help students learn the "what if" capabilities using a model-based approach to understanding a complex system. In this section, we focus on the design and development of simulation models for teaching scenarios and conditions that, due to their complexity and architectural requirements, can neither be easily demonstrated using traditional teaching approaches (e.g., case studies) nor readily implemented using pre-existing platforms such as Second Life. These models reflect a bottom-up approach to modeling and can be used to study the evolution of a phenomenon and understand the impact on various outcome measures with scientific rigor and depth. They typically need to be of a relatively smaller scale, allowing students to appreciate applications in a domain close to their situation.

In what follows, we illustrate how a simulation-based model-driven DSS can be designed for educating and training purposes through an example of modeling the problem of managerial information overload (Rutkowski \& Saunders, 2011) and interruptions resulting specifically from excessive workplace email processing. We briefly describe the user-centric design process for such a system and explain how it can be utilized to accomplish learning associated with the phenomenon under study.

The development of this model is motivated by the fact that the sheer volume of emails that demand knowledge workers' attention, in combination with poor choices in the timing of email processing, is one of the leading causes of several major workplace problems such as information overload, stress, reduced productivity, and prolonged task completion times. Though some emails may require very quick responses, checking emails almost continuously may lead to interruptions in regular knowledge work. Thus, addressing the critical problem of the timing of email processing can make a significant difference in an organization's productivity. Using a simulationbased DSS can help users understand the impact of using different email processing strategies 
(EPSs) in different work environments. This can not only improve the way workers deal with their emails but also make the knowledge workers' overall workday more productive. It is therefore important to understand how such a model can be designed.

Establishing time-based controls allows for better attention allocation, a scarce resource in modern organizations (Davenport \& Beck, 2000). A user can evaluate several variations of EPSs and identify the policy that results in the best outcome. For example, one approach for knowledge workers is to process their email in a single batch - once per day. Another strategy is to split email hours into four time slots of equal duration. Continual email processing represents another extreme of email processing, i.e., emails are processed as soon as they arrive. Other variations can also be compared and evaluated.

Other major components of the model include modeling of different categories of emails. For example, all incoming emails can be classified into two main types: those that elicit a response from the recipient and those that do not. Emails that require a response can further be classified into two types based upon the time it takes one to process them: complex emails that require a relatively long time to process and simple emails that can be processed in quickly. Emails could also be assumed to have different values depending upon how old they are. An email may provide maximum value to an organization or a knowledge worker if it is processed while it is fresh, for example, an email inviting someone to lunch in an hour. Some emails processed during their "second" life phase result in a positive value that is less than the maximum but greater than zero. Other emails may not result in any value if they are processed overly late. Yet another component of the model may classify all emails into three major categories based on their urgency level: high, moderate, and low urgency.

After designing various components of the model, the logic behind the flow of various entities within the model needs to be developed. This involves modeling the processing of primary (work) tasks, emails, and interruptions process. Each type of email undergoes a cycle of processing before it gets resolved. The length and nature of this cycle depends upon the type of email, as described earlier. For instance, emails that require a response go through more phases of processing than emails that do not require any response.

In addition to evaluating the performance of individual knowledge workers, such simulationbased DSS models can also be scaled up to experiment with and compare the network level performance with respect to various time-based scheduling approaches for processing emails. These models can be designed to be scalable and extended in scope to analyze knowledge networks with different structural characteristics and properties. For example, we can compare the performance of email processing strategies in homogeneous and heterogeneous networks. In a "homogeneous email network", all knowledge workers have similar email processing loads, whereas in a heterogeneous email network, knowledge workers differ in their email processing loads. However, scalability of such models requires prior planning during early design phases.

The use of such simulations in a classroom can facilitate a practice-oriented learning approach as students get to engage in experimenting with the phenomenon in multiple ways and explore heuristic approaches to improve performance (Gibson \& Kruse, 2011; Saulnier, 2011). These models could support a combined method of inductive and deductive learning in the classroom. In our example, such models can be used by instructors in delivering the central concept of information overload and identifying ways to mitigate its negative effect. In particular, after introducing the general problem of information overload and interruptions to students, a specific instance of the problem associated with managing emails in parallel with other knowledge tasks is described. The students then either engage in the development of a model or experiment with the model provided by the instructor. Students can alter parameters and conditions in the model and use the simulation software to explore and understand the impact of specific email processing strategies 
in different "what-if" scenarios such as high, moderate, or low overload. The students thus learn how to solve problems and explore alternative, heuristic solutions along with the secondary goal of understanding to use simulation methodologies. The focus of teaching component could be either on detailing the model architecture, or on the learning associated with the phenomenon under study (in this case, it is information overload) or even on the usability or user effectiveness associated with the model use.

\section{Designing Course Curriculum for a Technology-Rich Environment}

The challenge for a modern educator, who is willing to make use of technology-rich tools and get the teaching benefits of a technology-rich environment, is how to integrate the above discussed tools and practices in a curriculum, combine them with the existing, traditional methods, and provide new active learning opportunities for students. Without a well-built curriculum, the use of simulation modeling, game-based learning approaches, and a virtual learning environment could even obstruct the learning process. Designing a curriculum that ensures active learning processes and achievement of the conceived learning goals has become an important stage in the process of successful employment of these innovative tools.

In this section we contribute to the existing research on innovative teaching by presenting a new approach to building a curriculum using Causal Mapping. We do so by resorting to an experiential study applied for teaching Operations Management course. The Operations Management field serves as a suitable empirical setting for our research objective as it is faced with the challenge to reassess the inter-relations between different areas traditionally taught in this course. This field has taken many turns throughout its history: it started with Taylor's principles of scientific management and engineering blueprints, then it was influenced by industrial engineering concepts and further on by mathematical models coming from operations research, and recently went through an excitement around supply chain management, organizational transformation, and service management (Hayes, Bouzdine-Chameeva, Hill, Scavarda, \& Goldstein, 2007). Beyond doubt, it is appropriate to suggest revisions to the Operations Management curriculum to meet the needs of the future and reinforce learning via new opportunities offered by the available simulation tools in a technology-rich environment.

Causal Mapping has proved to be an efficient and practical tool for building a course curriculum (Hayes et al., 2007; Scavarda, Bouzdine-Chameeva, Goldstein, Hays, \& Hill, 2006). It is known to be especially valuable for understanding critical relationships in interdisciplinary fields and could be particularly adapted to integrate the benefits of simulation models and theories, gamesbased learning, and classic studies. Mapping concepts can help develop multi-disciplinary courses that are well integrated, logically sequenced, and have continuity.

Instructors frequently use the concepts mapping technique to provide meaning to students by integrating concepts and supporting a holistic style of learning. Concept maps help "teachers design units of study that are meaningful, relevant, pedagogically sound, and interesting to students" (Martin, 1994) and also help "the teacher to explain why a particular concept is worth knowing and how it relates to theoretical and practical issues both within the discipline and without" (Allen, Hoffman, Kompella, \& Sticht, 1993). This indicates that mapping could be especially important in the process of integrating simulation modeling and game techniques and/or introducing virtual teaching environments within interdisciplinary courses.

A joint project was developed by the University of St Thomas and the University of Minnesota (USA), the Royal Melbourne Institute of Technology (Australia), and BEM Bordeaux Management School in France. An innovative inductive approach for creating/revising a course curriculum was based on the newly-developed Collective Causal Mapping Methodology (CCMM) sug- 
gested in Scavarda et al. (2006). The collective causal map is based on expert opinions collected across a variety of sub-disciplines in the field of Operations Management (e.g., service management, quality management, inventory management) as well as related fields (e.g., industrial engineering, MIS, project management). In particular, the collective causal map was built by eliciting opinions of over 250 academics and practitioners (about $80 \%$ academics and about $20 \%$ practitioners) representing 63 countries and 173 universities. The "electronic expert community" of respondents to the study is diverse and representative in terms of expertise, discipline, subdiscipline, and geography. Their contribution to the curriculum development enhances the way Operations Management is taught and facilitates students' comprehension of the interacting parts of this multi-disciplinary course.

Using the CCMM innovative approach of curriculum building, we come up with a graphical course curriculum design, a compilation of the relationships and dependencies among interacting parts forming the multi-disciplinary field of Operations Management. It also combines theoretical knowledge, practical investigations, and technology-based experiences. Ideally, this framework serves a multi-disciplinary field in three ways: provides a better understanding of the core principles of the field, helps us better communicate the field to others, including our students, and prepares our students to meet the challenges of an increasingly information-intensive and globallycompetitive environment. It can aid instructors in determining which topics should be taught in a course, how these topics might be grouped and sequenced, and the important inter-relationships among the topics that should be stressed.

The identified factors (see Figure 2) determine the main sub-fields within Operations Management and these factors can be used to determine the content and sequencing of advanced Operations Management courses as well as to define the appropriate place for the innovative virtual interactive tools. In other words, while the identified factors can be used to determine the topical coverage of the core course, they can also serve as a map to guide the offerings of more advanced courses and a more innovative pedagogical teaching approach.

The new Operations Management curriculum provides a tool-kit of research-based best practices that have been proven effective in giving instructors a continuous improvement process in teaching the course. The causal map as a graphical syllabus (Figure 2) may serve also as a useful guide for students who are holistic learners. It has been also shown (Hayes et al., 2007) that causal mapping expands the range of processes for monitoring how students acquire knowledge of relationships and dependencies in the interacting parts that form a field of study. The "graphical" course design reveals numerous possibilities for assessment and evaluation of student performance. An instructor can have his/her students draw their own causal maps at the conclusion of the course to compare the students' maps to the expert map. The evaluation of a student's performance can be based also on covering the identified factors and their interactions.

We believe that using this type of an innovative approach to course curriculum development for fields such as systems engineering, operations management, and service sciences is especially important when we introduce virtual environments and tools. Asynchronous collection of information from geographically dispersed and diverse subject matter experts via Web technologies combined with causal mapping helps an educator to develop a well-thought course design. Built on experts' opinions, the resulting course design will reveal the advantages of each specific interactive tool and therefore contribute to the attainment of the course's learning objectives. 


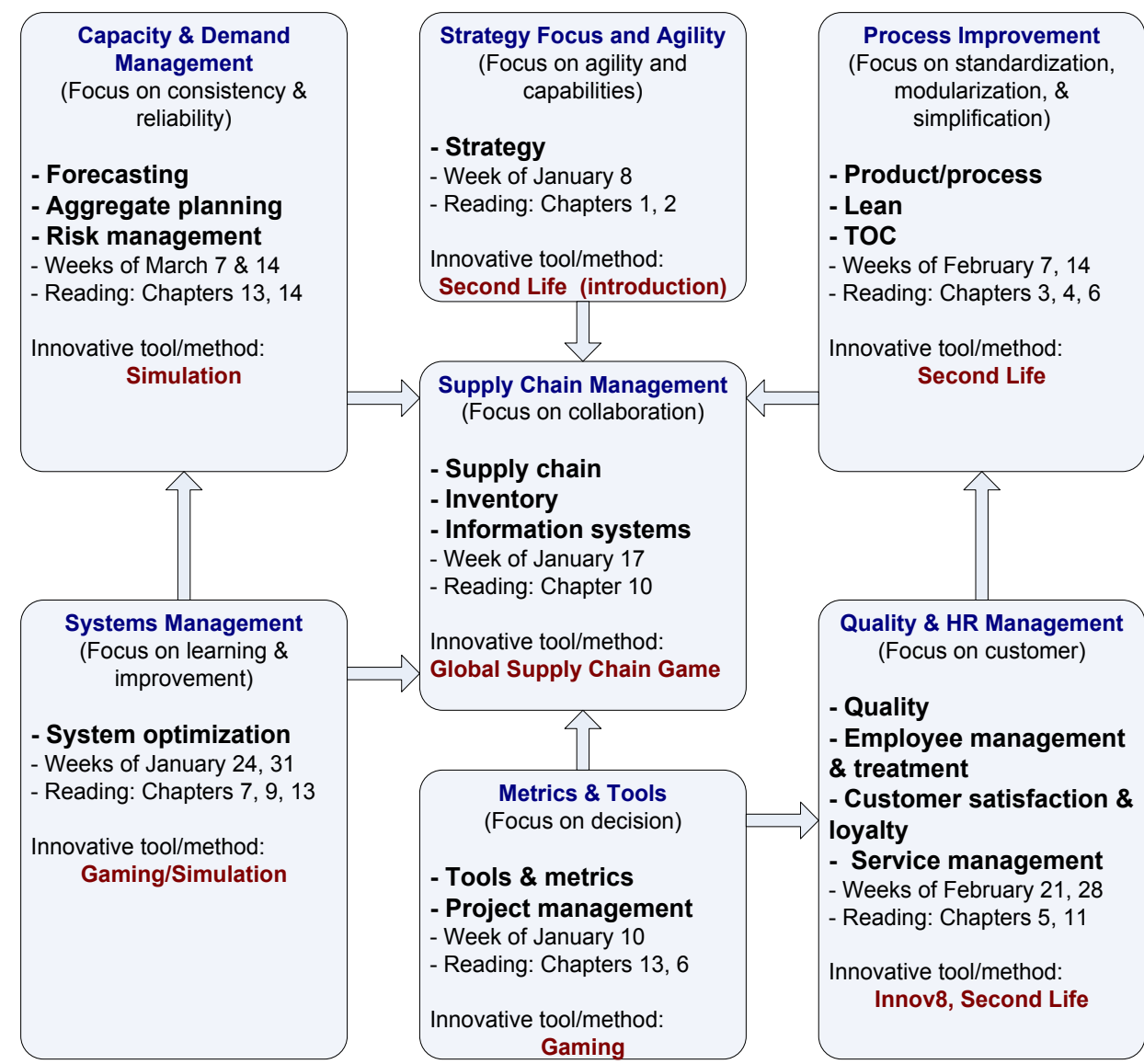

Figure 2: Graphical Operations Management Course Syllabus built on a causal map using the CCMM (adapted from Hayes et al., 2007) complemented with virtual interactive tools.

Although the employment of simulation models and game-based approaches has seen a strong rise during the recent years, the use of these innovative approaches is not always beneficial. Building a robust curriculum provides an educator with a possibility of examining and unearthing rich, context embedded processes that can serve as a base for adding valuable knowledge to the learning process. With these objectives, we resorted to an innovative inductive approach to designing graphical syllabus as a new course curriculum for a technology-rich environment.

\section{Implications and Conclusions}

This paper has described diverse pedagogical methods and approaches that, combined with appropriate software tools, have been used to teach modeling and decision making techniques. Different fields and subjects can benefit in different ways from simulations, game-based educational approaches, and virtual learning environments (e.g., Second Life, Innov8). For more technically and engineering oriented fields, simulation is a prominent way of teaching, experimenting, and dealing with complex systems. This is especially the case with highly complex systems whose multiple variables and their dynamic feedback promote uncertainty and unpredictability in behavior and interaction with the environment. For the business areas of supply-chain management and operations management, not only simulation, but also virtual learning environments and gamebased interactions hold significant educational potential. Although the border between a game and a simulation is increasingly blurring, one can distinguish where games deliver most effective results and where simulations can prove more efficacious. For example, for technical systems, especially complex engineering and infrastructure systems, simulation holds many benefits, while 
game-based approaches can be of great value in multi-actor networks, where managers, investors, policymakers, politicians, and other social groups interact and often pursue rather conflicting interests. Game-based approaches can be an essential learning tool to build up consensus and enhance the learning process as the actors can have different perceptions of the envisioned complex system.

The use of simulation modeling and various immersive game-based approaches can bring about a dramatic change in the students' learning behavior and learning outcomes (Mayo, 2009). Simulation and game-based methodologies are being effectively used to supplement teaching in courses such as operations management, supply chain modeling, and project management at the universities some of the co-authors are affiliated with. While the Second Life virtual experience accompanies the core MBA course on operations management over the entire term, the Global Supply Chain Game is frequently included in the curriculum as a concluding part of the course to summarize what was learnt and focus on the learning objectives in the final synthesis. The simulation modeling of excessive email processing is used to illustrate specific topics in the operations management course in its mid-term period. Similarly, in a systems engineering course, animation clips are used to explain certain concepts and games are used to mimic complex decision-making processes. Thus innovative tools are used on the level of specific topics rather than throughout the whole course. In another university, in the Systems Engineering program, both simulations and games play prominent, even central, roles. Systems engineering concerns complex systems design that is almost impossible to carry out without an extensive use of simulations - to study the performance of the system, manipulate its parameters, and examine the dynamics of its behavior. Complex systems engineering projects include different actors. The interaction of these actors, decision-making processes, negotiation, and policy making are all taught by using game-based approaches.

\section{Research Opportunities}

Each virtual tool or environment has its specific pedagogical objectives, and it is important to fit it neatly into the curriculum of an interdisciplinary course. Instructors revise and update their courses; they experiment with new approaches and tools, aiming to teach these courses in an interactive and innovative way and/or create new courses. However, systematic curriculum development or systematic review of the courses falls outside the expertise of nearly any university faculty. There are too many challenging questions to be answered: How to define learning goals? How to reflect the changes in the field? How to emulate real-world experience and introduce virtual environments? How to better structure the course? At what point in the course is the use of simulation modeling the most advantageous?

Innovative approaches need to be applied according to the course development guidelines to make the teaching of the course and the learning process more effective and more enjoyable for students. Using the new virtual interactive tools and environments requires a clear understanding of their place in a curriculum and their potential to facilitate the comprehension of the course topics and the attainment of the course objectives. Pedagogical innovations should thus follow a process of evaluating different strategies and measuring the impact of novel tools and new course designs on the students' learning outcomes.

Technology-inspired teaching, innovative pedagogical approaches, and tools and virtual environments are constantly changing. Many potential tools are in an emergent stage, slowly making their way into classrooms and university curriculum. A follow-up study will undoubtedly be needed to further explore and reveal more innovative ways of utilizing these tools. 


\section{References}

Allen, B. S., Hoffman, R. P., Kompella, J., \& Sticht, T. G. (1993). Computer-based mapping for curriculum development. Proceedings of Selected Research and Development Presentations at the Convention of the Association for Educational Communications and Technology, New Orleans, LA.

Aris, R. (1994). Mathematical modelling techniques. New York

Axelrod, R. (2003). Advancing the art of simulation in the social sciences. Japanese Journal for Management Information Systems, 12(3), 3-16.

Bekebrede, G., Mayer, I. S., Van Houten, S. P. A., Chin, R. T. H., \& Verbraeck, A. (2005). How serious are serious games? Some lessons from infra-games. In S. de Castell and J. Jensen (Eds.), Proceedings of DiGRA 2005 Conf. Changing Views: Worlds in Play, (pp. 1-7).

Bélisle, J.-F., \& Bodur, H. O. (2010). Avatars as information: Perception of consumers based on their avatars in virtual worlds. Psychology \& Marketing, 27(8), 741-765.

Bransford, J., Brown, A., \& Cocking, R. (Eds.). (2000). How people learn: Brain, mind, experience, and school. National Academy Press, Washington, D.C.

Byrne, M. D., Catrambone, R., \& Stasko, J. T. (1999). Evaluating animations as student aids in learning computer algorithms. Computers \& Education, 33(4), 253-278.

Coldwell, J., Craig, A., \& Goold, A. (2011) Using eTechnologies for active learning. Interdisciplinary Journal of Information, Knowledge, and Management, 6, 95-106. Retrieved from http://www.ijikm.org/Volume6/IJIKMv6p095-106Coldwell548.pdf

Corsi, T. M., Boyson, S., Verbraeck, A., Van Houten, S. P. A., Han, C., \& MacDonald, J. R. (2006). The real-time global supply chain game: New educational tool for developing supply chain management professionals. Transportation Journal, 45(3), 61-73.

Davenport, T. H., \& Beck, J. C. (2000). Getting the attention you need. Harvard Business Review, 78(5), 118-126.

De Nood, D., \& Attema, J. (2006). Second Life: The second life of virtual reality. The Hague, EPN - Electronic Highway Platform.

Foster, A. L. (2008). Using Second Life as platform for education: Professor Avatar. The Education Digest, 73(5), 12.

The Gartner Group. (2007). Press Release: Gartner says 80 percent of active internet users will have a "Second Life" in the virtual world by the end of 2011. Retrieved from http://www.gartner.com/it/page.jsp?id=503861

Gershenfeld, N. (1998). The nature of mathematical modeling. Cambridge: Cambridge University Press.

Gorry, G. A., \& Scott Morton, M. (1989). A framework for management information systems. Sloan Management Review, 49-61.

Gibson, D., \& Kruse, S. (2011). Next generation learning challenge: Simulating teaching. Educause Quaterly. Retrieved from http://www.educause.edu/ero/article/next-generation-learning-challengesimulating-teaching

Hake, R. (1998). Interactive-engagement vs. traditional methods: A 6,000-student survey of mechanics test data for introductory physics courses. American Journal of Physics, 66(1), 64-74.

Hayes, J., Bouzdine-Chameeva, T., Hill, A. V., Scavarda, A. J., \& Goldstein, S. M. (2007). Applying the collective causal mapping methodology to operations management curriculum development. The Decision Science Journal of Innovative Education, 5(2), 267-287.

Heijden, M. C. van der, Harten, A. van, Ebben, M. J. R., Saanen, Y. A., Valentin, E. C., \& Verbraeck, A. (2002). Using simulation to design an automated underground system for transporting freight around Schiphol Airport. Interfaces, 32(4), 1-19. 
Kirschner, P. A., Sweller, J., \& Clark, R. E. (2006). Why minimal guidance during instruction does not work: An analysis of the failure of constructivist, discovery, problem based, experiential, and inquirybased teaching. Educational Psychologist, 41(2), 75-86.

KZero Worldswide. (n.d.). Growth by age: Registered account growth by segment. Retrieved from http://www.slideshare.net/fullscreen/nicmitham/kzero-universe-q2-2011/5

Linden Lab. (2011). Second Life education: The virtual learning advantage. Retrieved from http://lecsstatic-secondlife-com.s3.amazonaws.com/work/SL-Edu-Brochure-010411.pdf

Maerki, H. U. (2008). Are business schools studying and teaching the right things? The Journal of Management Development 27(4), 425-430.

Marcus, D. C., \& Ray, B. (2006). Using massively multiplayer online role-playing games for online learning. Distance Education, 27(2), 187-196.

Martin, D. J., (1994). Concept mapping as an aid to lesson planning: A longitudinal study. Journal of Elementary Science Education, 6(2), 11-30.

Mayer, I., \& Veeneman, W. (Eds.). (2002). Games in a world of infrastructures, Chapter 2, pp. 17-37. The Netherlands: Eburon.

Mayo, M., J. (2009). Video games: A route to large-scale STEM education? Science, 323(5910), 79-82.

National Science Board. (2012). Science and Engineering Indicators 2012. Arlington VA: National Science Foundation (NSB 12-01).

Pettey, C. (2012). Personal communication via email with Christy Pettey of The Gartner Group regarding an update to the report released at the Gartner Symposium/ITxpo: Emerging Trends on April 24, 2007.

Piaget, J. (1970). Piaget's theory. In P. Mussen (Ed.), Carmichaels' manual of child psychology (3rd ed.), Vol. I. New York: Wiley.

Power, D., \& Sharda, R. (2007). Model-driven decision support systems: Concepts and research directions. Decision Support Systems, 43(3), 1044- 1061.

Royle, K. (2008). Game-based learning: A different perspective. Innovate: Journal of Online Education, $4(4)$.

Rutkowski, A. F., \& Saunders, C. (2011). Understanding overload: An emotional cognitive model. Proceedings of the 71st Academy of Management Conference 2011: West meets East: Enlightening, Balancing, Transcending, San Antonio: Academy of Management

Saulnier, D. (2011) A framework for assessing learning outcomes in online business simulations. Retrieved July 09, 2012, from http://saulnier.typepad.com/learning_technology/2007/12/a-framework-for.html

Saunders, C., Rutkowski, A.F., van Genuchten, M., Vogel, D., \& Molina Orrega, J. (2011). Virtual space and place: Theory and test. MIS Quarterly, 35(4), 1079-1098.

Scavarda, A. J., Bouzdine-Chameeva, T., Goldstein, S. M., Hays, J. M., \& Hill, A. V. (2006) Methodology for constructing collective causal maps. Decision Sciences, 37(2), 263-284.

Second Life education directory. (n.d.). In Wikipedia. Retrieved from http://wiki.secondlife.com/wiki/Second_Life_Education_Directory

Second Life work/success stories. (n.d.). In Wikipedia. Retrieved from http://wiki.secondlife.com/wiki/Second_Life_Work/Success_Stories

Seppanen, M. S., \& Kumar, S. (2002). Using simulation to teach business process design and improvements. Proceedings of the 2002 Winter Simulation Conference, 1809-1814.

Shim, J. P., Warkentin, M., Courtney, J. F., Power, D. J., Sharda, R., \& Carlsson, C. (2002). Past, present, and future of decision support technology. Decision Support Systems, 33(2), $111-126$.

Suh, K. S., Kim, H., \& Suh, E. K. (2011). What if your avatar looks like you? Dual-congruity perspectives for avatar use. MIS Quarterly, 35(3), 711-729. 
Tatnall, A., \& Burgess, S. (2007). Experiences in building and using decision-support systems in postgraduate university courses. Interdisciplinary Journal of Information, Knowledge, and Management, 2, $33-$ 42. Retrieved from http://www.ijikm.org/Volume2/IJIKMv2p033-042Tatnall279.pdf

Van Houten, S. P. A., Verbraeck, A., Boyson, S., \& Corsi, T. (2005). Training for today's supply chains: An introduction to the Distributor Game. In M. Kuhl, N. Steiger, F. Armstrong, \& J. Joines (Eds.), WSC'05: Proceedings of the 37th Winter Simulation Conference, Orlando, FL, USA, 2338-2345

Vygotsky, L. (1935/1978). Interaction between learning and development. In L. Vygotsky, Mind in society. Cambridge, MA: Harvard University Press.

Yang, S., Smith, B., \& Graham, G. (2008). Healthy video gaming: Oxymoron or possibility? Innovate: Journal of Online Education, 4(4).

Zeigler, B. P., Praehofer, H., \& Kim, T.G. (2000). Theory of modeling and simulation (2nd ed.). Academic Press.

Zyda, M. (2007). Creating a science of games. Communications of the ACM, 50(7), 26-29.

\section{Biographies}

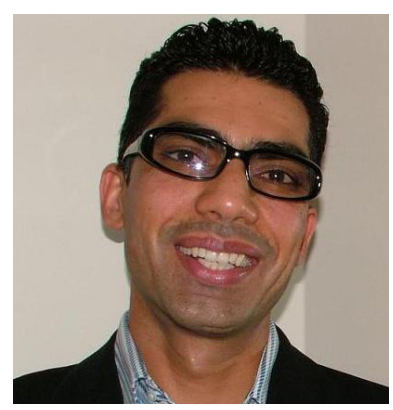

Joseph Barjis is an Associate at Delft University of Technology (Netherlands). He received his PhD from Moscow Technical University of Communication and Informatics, followed by 4 years of postDoctoral research at Delft University of Technology. His main research focus is on enterprise engineering, modeling and simulation, information systems design, and systems engineering. The offspring of his research resulted in 13 edited conference books, 14 book chapters, over 22 journal articles and editorials, guest editor of 9 special issues, and over 70 papers in fully peer refereed conference proceedings. He has been an invited speaker to a number of national and international forums, general chair of numerous international workshops and serving in the editorial board of many journals.

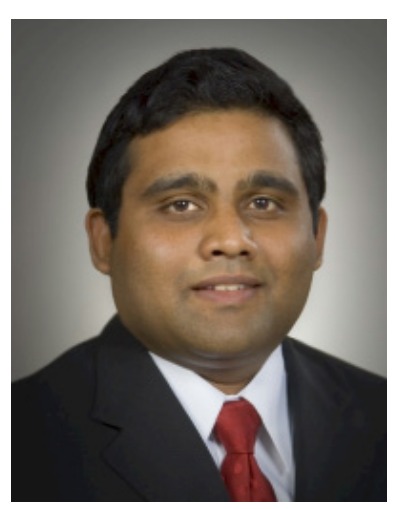

Ashish Gupta is an Associate Professor in School of Business at Minnesota State University Moorhead and holds visiting appointment in Biomedical Informatics Department at Arizona State University. He has been a visiting Research Scientist at Mayo Clinic. He received his $\mathrm{PhD}$ in Management Science and Information Systems from Oklahoma State University. He has published in several journals including Decision Support Systems, European Journal of Information Systems, Communications of AIS, Information Systems Frontiers, etc. He serves on the editorial boards of journals such IJDSST, IJITSA and served guest editor of Decision Support Systems on healthcare modeling. He serves on NIH and PICORI review panels and has co-chaired numerous conferences such as Symposium on Healthcare

Advancement in Research \& Practice (SHARP) -1.0, 2.0, EMOAS 2011 (London). Ashish is current President of Midwest AIS (2012-2013). His interests include critical care, EMR, patient portals, simulation, virtual world in health, clinical informatics and healthcare delivery. 


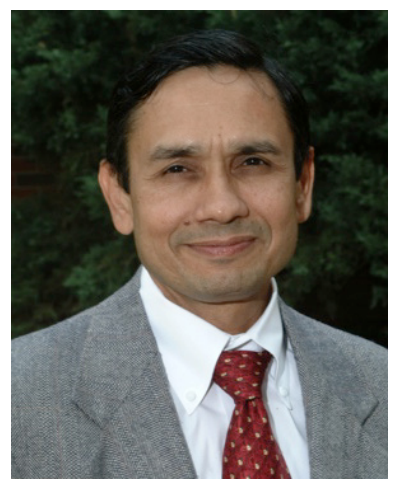

Ramesh Sharda is Director of the $\mathrm{PhD}$ in Business for Executives Program, the Institute for Research in Information Systems (IRIS), ConocoPhillips Chair and a Regents Professor of Management Science and Information Systems in the Spears School of Business at Oklahoma State University. His research has been published in major journals in management science and information systems including Management Science, Operations Research, Information Systems Research, Decision Support Systems, Interfaces, INFORMS Journal on Computing, and many others. He has coauthored two text books (Decision Support and Business Intelligence Systems, 9th edition, Prentice Hall and Business Intelligence: A Managerial Approach, 2nd Edition, Prentice Hall, 2010). He serves on the editorial boards of journals such as the INFORMS Journal on Computing, Decision Support Systems, ACM Transactions of MIS, and Information Systems Frontiers. Ramesh is also a cofounder of a company that produces virtual trade fairs, iTradeFair.com.

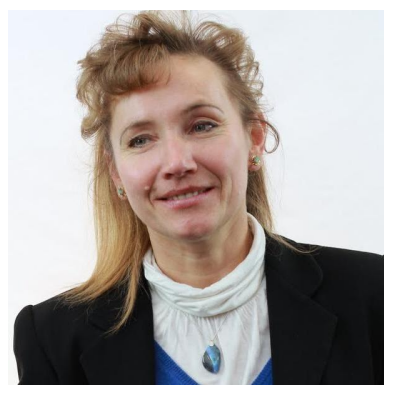

Dr. Tatiana Bouzdine-Chameeva has a Ph.D. in Applied Mathematics from Moscow University. She is currently a Senior Professor of Operations Management and Information Systems at BEM - Bordeaux Management School in France. She teaches courses in quantitative methods and optimization, decision analysis, project management and managerial decision-making. Professor BouzdineChameeva's research is in operations research field - the application of quantitative and qualitative (cognitive) methods to management problems. She extensively publishes in top journal such as Decision Sciences and European Journal of Operational Research.

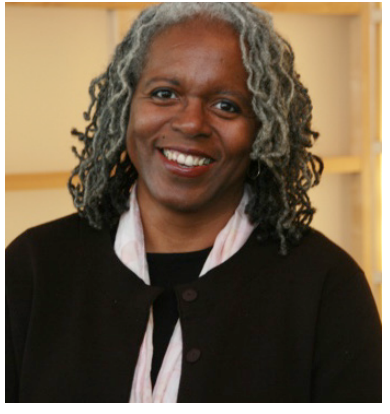

Dr. Lee is Clinical Assistant Professor of Operations and Supply Chain Management and Faculty Chair for Undergraduate Programs at Indiana University's Kelley School of Business Indianapolis. She received her doctorate in logistics, operations and materials management from the George Washington University in 2001, after a 20-year career in telecommunications where she held multiple managerial positions. She has published in such outlets as the Journal of Business and Industrial Marketing, the Journal of Virtual Worlds Research, the Journal of Healthcare Management, and Supply Chain Forum, published by the University of Lausanne. She serves on the Board of Advisors for the Business Program at Ivy Tech, Indiana's Community College system, the Organizing Committee of EOMAS, and is incoming Treasurer of the Midwest Decision Sciences Institute.

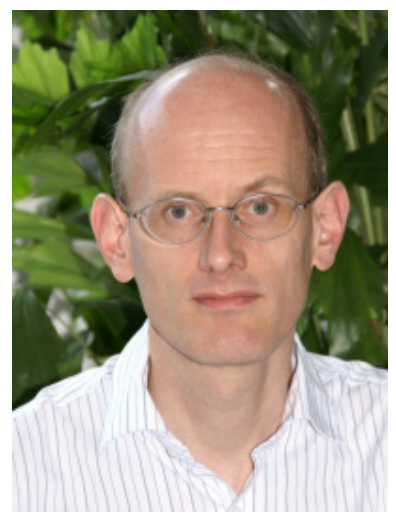

Alexander Verbraeck is a Full Professor in Systems and Simulation at Delft University of Technology and head of the simulation research group. Professor Verbraeck also serves as a part time full professor in supply chain management at the R.H. Smith School of Business of the University of Maryland. He is a specialist in discrete event simulation for real-time control of complex transportation systems and for modeling business systems. His current research focus is on generic libraries of object oriented simulation building blocks, on tools for Web-based simulation, and on the use of simulation models and virtual reality for serious gaming. 